\title{
The McCoy straight blade does not improve laryngoscopy and intubation in normal infants
} [La lame droite McCoy n'améliore pas la laryngoscopie ni l'intubation chez des enfants normaux]

Gabriella Iohom FCARCSI, Robert Franklin FCARCSI, William Casey FCARCSI, Barry Lyons FCARCSI

Purpose: The McCoy curved blade laryngoscope has been demonstrated to improve view at laryngoscopy in adults. A straightbladed version of this laryngoscope has recently been introduced into pediatric practice. The objective of this prospective, randomized study was to compare the intubating conditions afforded by the McCoy (\#I) straight blade laryngoscope with the conventional Miller (\# I) blade in neonates and infants.

Methods: Forty patients under six months of age, were randomized into two groups: one group $(n=20)$ had an initial laryngoscopy with the McCoy blade and then had a laryngoscopy and subsequent intubation using the Miller blade; the second group $(n=20)$ had an initial laryngoscopy with the Miller blade, followed by laryngoscopy and intubation using the McCoy blade. All intubations were performed by one anesthesiologist familiar with using both blades.

Results: The majority of patients (39 out of 40) had a similar or superior view (Cormack and Lehane classification) with the Miller when compared with the McCoy laryngoscope. Mean time to laryngoscopy was I4.9 (12.7) sec with the McCoy and 6.8 (2.07) sec with the Miller blade $(P=0.00 \mathrm{I})$, whereas mean time to intubation was 25.13 (1 0.4) sec with the McCoy and 12 (8.5) sec with the Miller blade $(P=0.014)$. There was no difference between the groups regarding desaturation and changes in heart rate during laryngoscopy and intubation.

Conclusion: Our data indicate that the McCoy blade has no advantage over the conventional pediatric Miller blade in normal infants.

Objectif: On sait que la lame courbe du laryngoscope McCoy peut améliorer la vue laryngoscopique chez les adultes. La version à lame droite du McCoy a été récemment introduite en pratique pédiatrique. Notre étude prospective et randomisée visait à comparer les conditions d'intubation fournies par la lame droite McCoy (\# I) et la lame Miller traditionnelle (\# I) chez des nouveau-nés et de jeunes enfants.
Méthode : Quarante patients de moins de six mois ont été répartis en deux groupes: dans le premier $(n=20)$, on a réalisé une première laryngoscopie avec la lame McCoy, puis une laryngoscopie et une intubation avec la lame Miller; dans le second $(n=20)$, on a d'abord utilisé la lame Miller, puis la lame McCoy pour une laryngoscopie et une intubation. Un anesthésiologiste habitué aux deux lames a fait toutes les intubations.

Résultats : Chez 39 patients sur 40, une exposition similaire ou supérieure (classification de Cormack et Lehane) a été obtenue avec la lame Miller comparée à la lame McCoy. La laryngoscopie a duré en moyenne 14,9 (12,7) sec avec la lame McCoy et de 6,8 (2,07) sec avec la lame Miller $(P=0,001)$, tandis que l'intubation a été de $25,13(10,4)$ sec avec la lame McCoy et de $12(8,5)$ sec avec la lame Miller $(P=0,0 / 4)$. Aucune différence intergroupe n'a été notée quant à la désaturation et aux modifications de la fréquence cardiaque pendant la laryngoscopie et l'intubation.

Conclusion : La lame McCoy ne présente pas d'avantages sur la lame pédiatrique Miller traditionnelle utilisée chez de jeunes enfants normaux.
HE McCoy levering curved blade laryngoscope (sizes 3 and 4 ) was invented in the early 1990's. It allows mechanical manipulation of the blade tip during laryngoscopy in an effort to reduce the amount of force necessary for visualization of the larynx. ${ }^{1,2}$ During laryngoscopy, elevation of the epiglottis is possible by lifting the blade tip as a result of pressing the lever on the handle rather than by direct force on the entire blade. It has been demonstrated to improve view at laryngoscopy in adults, particularly in those cases where anatomical features render this difficult. ${ }^{3}$ A straight bladed size 1

From the Department of Anaesthesia and Intensive Care, Our Lady's Hospital for Sick Children, Dublin, Ireland.

Address correspondence to: Dr. G. Iohom, Department of Anaesthesia, Cork University Hospital, Cork, Ireland. Phone: $+353-21-$

4922134; Fax: +353-21-4546434; E-mail: iohom@hotmail.com

Accepted for publication December 5, 2002.

Revision accepted September 10, 2003. 
version of this laryngoscope has recently been introduced into pediatric practice. We undertook this study to compare the intubating conditions of the straight McCoy blade with a conventional Miller blade (Figure $1)$, in infants aged zero to six months, with regards to quality of the laryngeal view and speed of intubation. We hypothesized that the McCoy laryngoscope would provide a better view of the laryngeal inlet and would facilitate tracheal intubation in infants.

\section{Methods}

Following Institutional Ethics Committee approval and written parental consent, 40 ASA I and II pediatric patients aged zero to six months scheduled for elective general anesthesia requiring tracheal intubation were evaluated. Exclusion criteria included obvious abnormalities of the head or neck, refusal of consent or an indication for rapid sequence induction. All laryngoscopies were performed by the main investigator experienced with the use of both Miller and adult McCoy laryngoscopes (three months experience with pediatric and extensive experience with adult McCoy). Both blades were inserted in the same fashion, beyond (posterior to) the epiglottis.

Characteristics of a size 1 straight McCoy blade (InterMed Penlon Ltd, Radley Road, Abingdon, Oxon, England) are: width $2.05 \mathrm{~cm}$ at base and 0.93 $\mathrm{cm}$ at the very tip, blade thickness $0.8 \mathrm{~cm}$, length of blade $11.14 \mathrm{~cm}$, length of levering tip $1.98 \mathrm{~cm}$. The dimensions of the standard size 1 Miller blade (Shucman $^{\mathrm{TM}}$, Truphatek, Medivent Ltd, Lucan, Co. Dublin) are: width $1.75 \mathrm{~cm}$ at base and $1.11 \mathrm{~cm}$ at the tip, thickness $0.92 \mathrm{~cm}$, length $10.28 \mathrm{~cm}$. The McCoy laryngoscope is currently 12 -fold more expensive than the Miller laryngoscope.

All patients had standard monitoring including electrocardiogram and pulse oximetry (Siemens 900, Siemens Medical Systems, Inc Electromedical Group, Danvers, MA, USA). Anesthesia was induced with sevoflurane $8 \%$ in a $40 \% \mathrm{O}_{2} / \mathrm{N}_{2} \mathrm{O}$ mixture delivered using weight appropriate gas flows via an Ayre's $\mathrm{T}$ piece for four minutes (Siemens Elema $A B$ Electromedical Systems Division, Solna, Sweden). Sevoflurane induction time was chosen to exceed the time needed to successfully intubate $80 \%$ of infants without muscle relaxant. ${ }^{4}$

Intravenous access was secured before intubation. No anticholinergic or neuromuscular blocking agent was used prior to intubation. Patients were randomized using a random number table into two groups: one group had an initial laryngoscopy using the McCoy blade and then had a laryngoscopy and intubation with the Miller blade; the second group had an

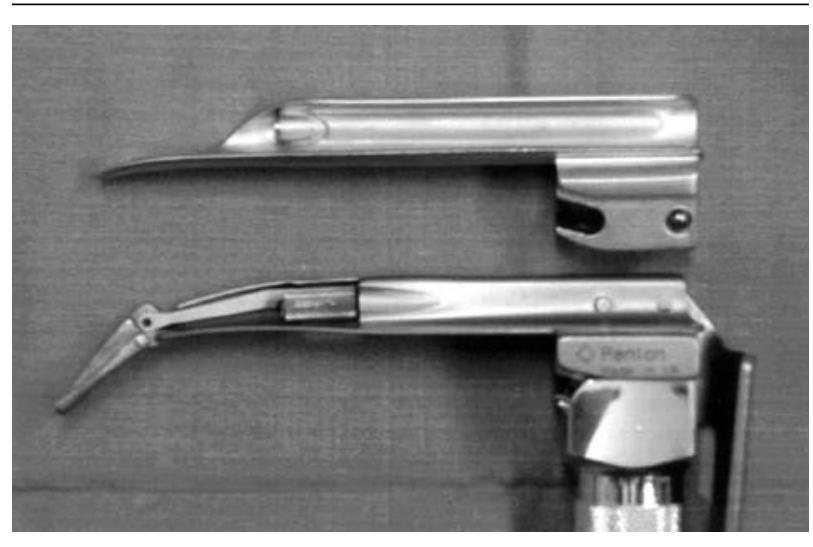

FIGURE 1 A Miller \#1 and a McCoy \#l blade with the lever activated.

initial laryngoscopy with the Miller blade and then had a laryngoscopy and intubation using the McCoy blade. Inhalational anesthesia was re-established for one minute before intubation via the second technique was performed. Both times to best laryngoscopic view and the grade of the laryngeal view (I-IV) according to the Cormack and Lehane classification were recorded. Despite the fact that this scoring system has not been thoroughly investigated and validated in children, the laryngoscopic grading system of Cormack and Lehane offers a reasonable means of describing visualization of the larynx..$^{5,6}$

Passing a size 3.5 endotracheal tube was attempted in all cases. Endpoints examined included success of intubation, time required to intubate, laryngeal view at intubation, the need for activation of the levering tip and need for external pressure, number of attempts at intubation. The levering tip was activated when a laryngeal view grade > II was encountered. Similarly, external pressure was applied under the same circumstances, in this order. The time to intubate was clearly defined as the time from lifting of the facemask to the re-establishment of ventilation via the endotracheal tube as confirmed by the presence of end-tidal carbon dioxide $\left(\mathrm{CO}_{2}\right)$. The times were measured using a stopwatch by an observer blinded to group assignment. Where two attempts were made to intubate, the time to intubation is reflected by the time of the successful attempt. Maximal changes (from baseline) in heart rate and oxygen saturation $\left(\mathrm{SpO}_{2}\right)$ occurring during laryngoscopy were recorded by the same observer.

In the absence of pediatric data with the McCoy laryngoscope, the sample size calculation was performed based on a similar study evaluating the adult 
TABLE I Demographic characteristics in the studied patient population

\begin{tabular}{lll}
\hline & Miller group $(n=20)$ & McCoy group $(n=20)$ \\
\hline Age (months) & $3.75(1.6)$ & $3.65(1.9)$ \\
Weight $(\mathrm{kg})$ & $6.18(1.5)$ & $6.30(2.1)$ \\
Male:female ratio & $15: 5$ & $15: 5$ \\
\hline
\end{tabular}

Data are expressed as mean (SD). No statistical difference between groups.

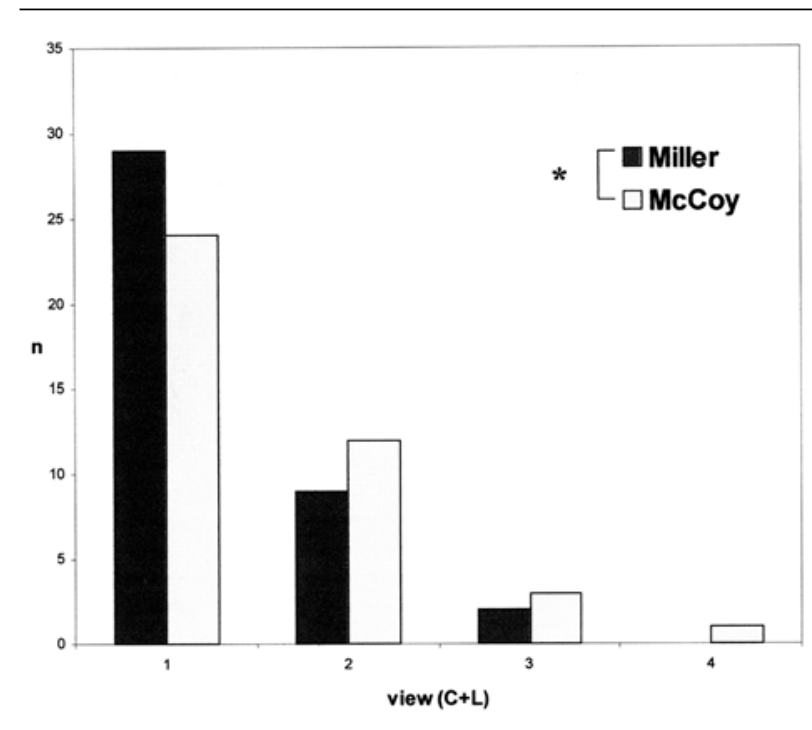

FIGURE 2 Best view at laryngoscopy

A total of 40 laryngoscopies were performed with both laryngoscopes. In 39 out of 40 cases the Miller laryngoscope provided a superior view (Chi square $=10.45$ with three degrees of freedom, $\left.{ }^{*} P=0.019\right) . \mathrm{C}+\mathrm{L}=$ Cormack and Lehane.

Bullard laryngoscope in children; ${ }^{7}$ using $\alpha=0.05$ and $B=0.2$ a sample size of 40 patients was deemed to be sufficient. The groups were then analyzed using patients as their own controls with respect to grading of laryngeal view, while heart rate and $\mathrm{SpO}_{2}$ changes during intubation were compared between the two groups. Times to laryngoscopy and intubation were compared for each laryngoscope used. Students t test, Chi square, Fishers exact test, Kruskal-Wallis test and repeated measures ANOVA were used as appropriate. $P<0.05$ was considered significant.

\section{Results}

The two groups were similar with respect to age, weight and gender (Table I). No patient had obvious craniofacial abnormalities. All infants were intubated

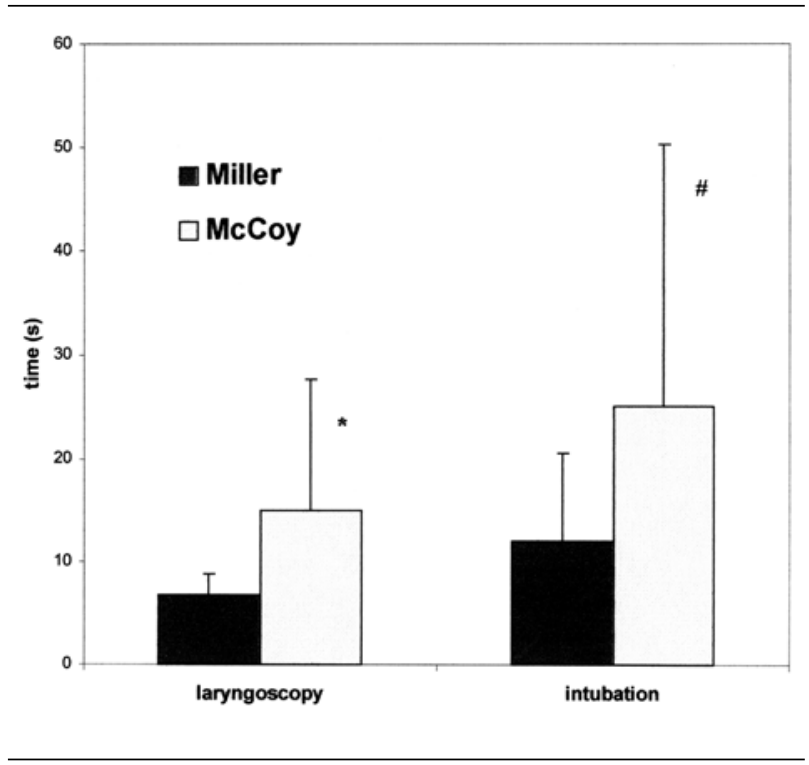

FIGURE 3 Times to laryngoscopy and intubation

Data are expressed as mean (SD). ${ }^{*} P=0.001$ in the McCoy group compared to Miller for laryngoscopy. $\# P=0.014$ for intubation in the McCoy group compared to the Miller group.

with a size 3.5 endotracheal tube. This didn't have to be downsized in any case during the study period. Figure 2 displays the best laryngoscopic views obtained according to the Cormack and Lehane classification. In the majority of cases the Miller blade produced the same or superior quality laryngeal view than the McCoy blade: view was superior with the Miller by one grade in 19 of 40 ; the same in 20 of 40 , and superior with the McCoy blade in one of 40 laryngoscopies. The lever was activated on 19 occasions for either laryngoscopy or intubation and improved the view in 13 cases, but this was superior to the view achieved by the Miller laryngoscope in one case only. One baby in each group required two attempts to intubate. There was a failed intubation with the McCoy blade, where the view was not enhanced by external laryngeal pressure. The trachea was eventually intubated using the Miller blade while applying external tracheal pressure in this infant.

In one case the McCoy laryngoscope with the lever activated transformed a grade III into a grade II laryngeal view. However, further external pressure was required to facilitate tracheal intubation.

The mean times to achieve the best laryngeal view and times to intubation in the studied population are shown in Figure 3. Both mean time to laryngoscopy and intubation were longer when using the McCoy blade $(P=0.001$ and $P=0.014$, respectively). 
TABLE II Changes in heart rate and $\mathrm{SpO}_{2}$ during laryngoscopy and intubation

\begin{tabular}{|c|c|c|c|}
\hline & & Miller laryngoscope & McCoy laryngoscope \\
\hline \multirow[t]{4}{*}{ Heart rate (beats. $\left.\mathrm{min}^{-1}\right)$} & Pre-laryngoscopy & $144.1(19.1)$ & $150.1(20.5)$ \\
\hline & Post-laryngoscopy & $135.1(20.1)^{*}$ & $141.9(19.9)^{*}$ \\
\hline & Pre-intubation & $142.9(18.9)$ & $136.5(21.4)$ \\
\hline & Post-intubation & $134.5(18.1)^{*}$ & $126.5(20.6)^{*}$ \\
\hline \multirow[t]{4}{*}{$\mathrm{SpO}_{2}(\%)$} & Pre-laryngoscopy & $99.8(0.5)$ & $99.3(1.1)$ \\
\hline & Post-laryngoscopy & $97.1(2.5) *$ & $94.6(8.3)^{*}$ \\
\hline & Pre-intubation & $98.4(1.7)$ & $98.3(1.5)$ \\
\hline & Post-intubation & $92.0(10.5)^{*}$ & $92.7(8.4)^{*}$ \\
\hline
\end{tabular}

All data are expressed as mean $(\mathrm{SD}) . \mathrm{SpO}_{2}=$ oxygen saturation; ${ }^{\star} P<0.05$ compared to pre-manipulation values respectively. No difference between groups was found.

No patient suffered any life threatening bradycardia or any episode of laryngospasm during the course of the study.

Table II displays the mean changes in heart rate and $\mathrm{SpO}_{2}$ during laryngoscopy and intubation. Heart rate and $\mathrm{SpO}_{2}$ decreased immediately after intubation but were not different between groups.

\section{Discussion}

This is the first study aimed to evaluate the infant straight bladed McCoy laryngoscope in the clinical setting. However, when compared to the conventional Miller blade, it did not improve intubating conditions. A single operator, with experience of both blades, was chosen to eliminate interobserver variability. Although this anesthesiologist had extensive experience with the adult McCoy blade, there was only a three-month lead-in period to become proficient with the straight blade version. While it may be argued that the McCoy straight blade may have suffered in this study because of relative unfamiliarity, it is not unreasonable to expect that an experienced anesthesiologist could become acceptably competent with a novel laryngoscope within this timeframe.

As each patient had two laryngoscopies (one with each blade) they thus acted as their own controls with regards to the laryngeal view.

A limitation of this study, as with most studies regarding airway techniques, is the fact that our patients had no obvious airway abnormalities and thus extrapolation of these results to infants with airway abnormalities may not be applicable. Also, based on standard practice with the Miller blade, we used both blades in the same fashion, posterior to the epiglottis. It is possible that this is not the optimal position for the McCoy blade. In its inactivated position, the McCoy blade provides a poorer view than the Miller blade. This finding is similar to that obtained with the routine use of the McCoy laryngoscope in adults, when in its inactivated position it does not appear to behave identically to the Macintosh blade. ${ }^{8,9}$ Positioning the tip of the straight blade anterior to the epiglottis in infants may allow manipulation of the epiglottis with greater facility, but this needs further study. The curved size \#2 blade for older children is available for use in such fashion.

The role of the McCoy laryngoscope in adult practice has been extensively studied. It has been shown to be a useful additional aid to laryngeal visualization, ${ }^{3}$ to fibreoptic intubation ${ }^{10}$ and invaluable in patients with limited neck extension. ${ }^{11}$ Furthermore it has been suggested that it causes the least stress response during laryngoscopy. ${ }^{12}$ More recently, the McCoy laryngoscope proved useful to aid intubation in about half of the patients with a grade III view at laryngoscopy but unlikely to improve a grade IV view. ${ }^{13}$

The usefulness of the straight McCoy blade in the neonatal setting remains unclear. There are no pointers from our present study to suggest that the neonatal McCoy laryngoscope would be a useful addition to our intubating armamentarium. It may have a role in reducing the stress response at intubation, but we found no hemodynamic indicators of this. Given its bulky design it may be more appropriate for use in an older age group. This may warrant further investigation.

With careful preoperative evaluation and planning, the unexpected difficult pediatric airway should be a rare event. Because the unexpected difficult airway occurs after beginning an anesthetic procedure, many of the management decisions required for the anticipated difficult airway have been made. Of primary importance is maintaining adequate oxygenation while a definitive course of action is pursued. Many techniques and devices for managing a difficult airway have been recommended. Previous experience in normal airways can render these devices valuable adjuncts in difficult airway management. ${ }^{14}$ 
In conclusion, our data indicate that the straight bladed neonatal McCoy laryngoscope does not appear to offer any advantage over the conventional Miller laryngoscope and may delay endotracheal intubation in a population of normal infants.

\section{References}

l McCoy EP, Mirakbur RK. The levering laryngoscope. Anaesthesia 1993; 48: 516-9.

2 McCoy E. The McCoy laryngoscope (Letter). Anaesthesia 1996; 51: 990.

3 Tuckey JP, Cook TM, Render CA. Forum. An evaluation of the levering laryngoscope. Anaesthesia 1996; 51: 71-3.

4 Politis GD, Frankland MJ, James RL, ReVille JF, Rieker $M P$, Petree BC. Factors associated with successful tracheal intubation of children with sevoflurane and no muscle relaxant. Anesth Analg 2002; 95: 615-20.

5 Wheeler M, Cote CJ, Todres ID. Pediatric airway. In: Cote CJ, Todres ID, Goudsouzian NG, Ryan JF (Eds.). A Practice of Anesthesia for Infants and Children. Philadelphia: W.B. Saunders; 2001: 99.

6 Marraro G. Airway management. In: Bissonette B, Dalens BJ (Eds.). Pediatric Anesthesia: Principles and Practice. New York: McGraw Hill; 2002: 788.

7 Shulman B, Connelly NR. The adult Bullard laryngoscope as an alternative to the Wis-Hipple $1 \frac{1 / 2}{2}$ in paediatric patients. Paediatr Anaesth 2000; 10: 41-5.

8 Cook TM, Tuckey JP. A comparison between the Macintosh and the McCoy laryngoscope blades. Anaesthesia 1996; 51: 977-80.

9 Leon $O$, Benhamou D. Improvement of glottis visualization with a McCoy blade (French). Ann Fr Anesth Reanim 1998; 17: 68-71.

10 Asai T, Matsumoto S, Shingu K. Use of the McCoy laryngoscope or fingers to facilitate fibrescope-aided tracheal intubation. Anaesthesia 1998; 53: 903-5.

11 Uchida T, Hikawa $\Upsilon$, Saito $\Upsilon$, Yasuda K. The McCoy levering laryngoscope in patients with limited neck extension. Can J Anaesth 1997; 44: 674-6.

12 Castillo J, Castano J, Escolano F, Arilla M. Cardio-circulatory response to laryngoscopy. Comparitive study between Macintosh and McCoy laryngoscopes (Spanish). Rev Esp Anestesiol Reanim 1996; 43: 219-21.

13 Chrisholm DG, Calder I. Experience with the McCoy laryngoscope in difficult laryngoscopy. Anaesthesia 1997; 52: 906-8.

14 Randell T, Maattanen M, Kytta J. The best view at laryngoscopy using the McCoy laryngoscope with and without cricoid pressure. Anaesthesia 1998; 53: 536-9. 